\title{
A rare presentation of Pulmonary Lymphangitic Carcinomatosis in Cancer of Lip: Case Report
}

\author{
Sajith Babu ${ }^{1 *}$, Satheeshan B ${ }^{1}$, Geetha $M^{2}$ and Surij Salih ${ }^{1}$
}

\begin{abstract}
Squamous cell carcinoma of lip is a common malignancy in Indian subcontinent. Metastatic spread is infrequent. Although advanced tumours spread to lymph nodes in the neck, it does not typically present with lung metastasis or with lymphangitic carcinomatosis. We describe a patient who developed cough and increasing dyspnoea while on treatment for carcinoma of lip. Chest $x$-ray and computed tomography were consistent with lymphangitic carcinomatosis. Lymphangitic carcinomatosis occurs with many different primary tumours and can rarely occur in oral cancers. This is the first report from carcinoma of lip.
\end{abstract}

\section{Background}

The common site of metastasis from most of the solid malignancies is lung. They usually appear as nodular lesions in radiologic images. In some patients, metastasis presents with interstitial spread and it is referred to as Pulmonary Lymphangitic Carcinomatosis (PLC). Head and neck cancers very rarely have lung metastasis in the form of PLC. Oropharyngeal and hypopharyngeal cancers have been reported to have such type of metastasis [1]. Cancer of lip is a common malignancy in Indian subcontinent mainly due to tobacco chewing and that these cancers are detected in early stages due to its visible location, a spread to lung is rare and they are of typical nodular metastases. PLC has not been reported till date from lip cancers in English literature. Here we report a case of PLC arising from cancer of the lower lip.

\section{Case Presentation}

60 year old gentleman with no co morbid illness, presented with a squamous cell carcinoma of lower lip. After evaluation, this was staged as T4 N2a M0, stage IV and was moderately differentiated squamous cell carcinoma. The X-ray of the chest was within normal limits. Wide excision of the lesion and reconstruction with a deltopectoral flap and a radical neck dissection on ipsilateral side was done. Postoperative histopathology was moderately differentiated squamous cell carcinoma

\footnotetext{
* Correspondence: drsajith@gmail.com

'Department of Surgical Oncology, Malabar Cancer Centre, Thalassery, Kerala Full list of author information is available at the end of the article
}

(pT4 N2a). After 4 weeks, post operative adjuvant concurrent chemo radiation was started with Cisplatin and radiotherapy in 2 Gy per fraction. While on radiotherapy, the patient developed severe dyspnoea of acute onset. There was no history of similar episode in the past and he was not a known patient of chronic obstructive pulmonary disease. He was afebrile and there was no cough or expectoration. Basic haematological study revealed normal haemogram. Clinically he was dyspnoeic, tachypnoeic and with tachycardia. On auscultation of the chest, there was scattered crackles and occasional ronchi. Air entry was equal on both sides. He was put on symptomatic care in the form of bronchodilators, antibiotics and nasal oxygen. Possibilities considered were acute bronchopneumonia and PLC. Chest radiograph revealed interstitial linear pattern from the hilum to the outer lung fields (Figure 1) and Kerley's B lines in both lungs suggesting PLC. A computerized tomography was taken which showed nodular septal thickening and it strongly suggested the diagnosis of PLC (Figure 2). Patient was given further courses of chemotherapy with Cisplatin, but with no improvement. The patient succumbed to disease on eighteenth day after the start of pulmonary symptoms.

\section{Discussion}

Lung metastasis from malignant tumours usually present as nodular lesions and rarely as Pulmonary Lymphangitic Carcinomatosis (PLC). PLC is characterised by diffuse spread of malignancy in the lung, causing inflammation of the lymph vessels. The first reported case of 


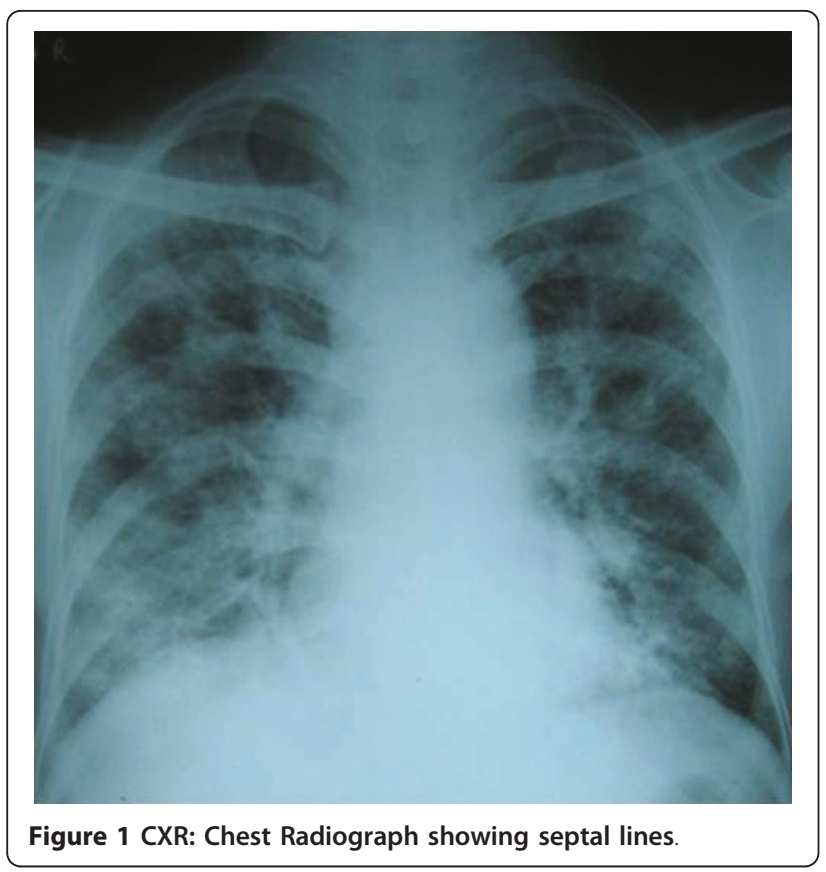

PLC was by Gabriel Andral in 1829 [2]. The diffusely infiltrating pattern of metastasis as seen in PLC occurs in $6-8 \%$ of lung metastases [3]. $80 \%$ of them are from adenocarcinomas. The common sites of primary from which PLC occurs are cancers of breast, bronchus, and stomach $[4,5]$. The other described sites with PLC are cancers from colon, pancreas, kidney, cervix, thyroid, larynx and hypopharynx [6-8].

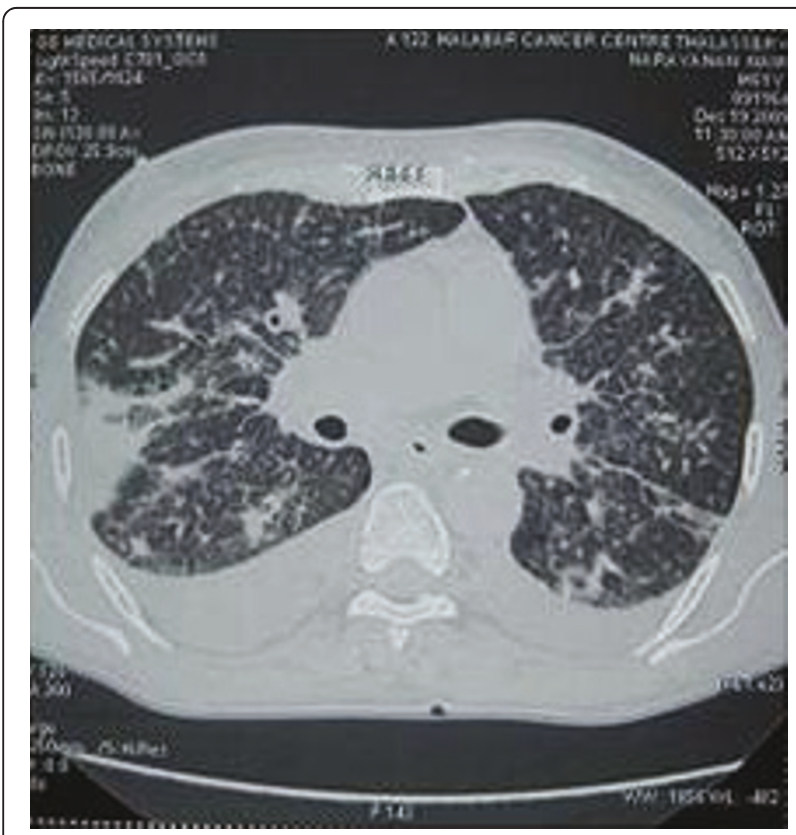

Figure 2 CT Scan: CT scan of thorax showing diffuse and bilateral findings.
The cancers of head and neck rarely show this type of metastasis. The exact reason is unknown. The described sites in head and neck region are larynx, hypopharynx and thyroid. Metastasis to lymph nodes from advanced cancers of lip is seen in about $44 \%$. Metastasis to lung is reported to be very low. There is no available report suggesting a PLC from oral cancers. PLC as metastatic feature as seen in the case described in this manuscript is an extremely rare presentation.

The pathophysiology is that the tumours spread by haematogenous route to the lung and then through the lymphatics within the lung. The lymphatics in the lung are seen in the peribronchovascular, centrilobular, interlobular and sub pleural regions. The tumour obstructs these lymphatic channels. The dilated lymphatic vessels due to oedema fluid, tumour secretion and the desmoplastic reaction by the tumour cells, produces interstitial thickening which is seen as streaks in imaging studies. The nodular pattern is due to the spread of tumour into the lung parenchyma as seen in usual lung metastases.

The clinical features of PLC are dyspnoea and nonproductive cough with crepitations and without features of consolidation. Chest X-ray shows septal lines (Kerley A and $\mathrm{B}$ lines). The differential diagnosis is interstitial lung disease, primary malignancy in the lung, pulmonary sarcoidosis and hypersensitivity pneumonitis. HRCT is the modality of choice for confirmation of the diagnosis. The findings in CT scan are - thickening of interlobular septa, fissures and bronchovascular bundles. These findings may be seen as limited or diffuse and may involve unilateral or bilateral lungs. The radiologic picture may be symmetric or asymmetric in both lungs. The other findings are nodularity in pleura and ground glass opacity [9]. The possibility of interstitial lung disease is to be considered and ruled out. Prakash $\mathrm{P}$ et al described the use of PET/CT in diagnosing PLC. In a study of 35, they found that PET/CT has high specificity in detection of pulmonary lymphangitic carcinomatosis [10].

Histopathological examinations show interstitial oedema and fibrosis along with malignant cells and are found usually on postmortem biopsy. Since the radiological finding in a patient with malignant disease elsewhere is suggestive, a biopsy of the lung is not mandatory.

PLC often presents in the late stages of malignancy and it indicates poor prognosis. The treatment option in PLC is with chemotherapy. Cisplatin have been found to be effective [11].

\section{Conclusion}

Pulmonary Lymphangitic Carcinomatosis may also occur rarely in patients with oral cancers as seen in our patient and its prognosis is very poor even with treatment with chemotherapy. 


\section{Consent}

Written informed consent was obtained from the patient for publication of this case report and accompanying images. A copy of the written consent is available for review by the Editor-in-Chief of this journal.

\section{Author details}

${ }^{1}$ Department of Surgical Oncology, Malabar Cancer Centre, Thalassery, Kerala. ${ }^{2}$ Department of Radiation Oncology, Malabar Cancer Centre, Thalassery, Kerala.

\section{Authors' contributions}

SB prepared the manuscript and the literature search, GM reviewed and edited the manuscript, ST corrected and revised the manuscript, SS: reviewed the manuscript. All authors read and approved the final manuscript.

\section{Competing interests}

The authors declare that they have no competing interests.

Received: 8 March 2011 Accepted: 14 July 2011 Published: 14 July 2011

\section{References}

1. Zieske LA, Myers EN, Brown BM: Pulmonary lymphangitic carcinomatosis from hypopharyngeal adenosquamous carcinoma. Head Neck Surg 1988, 10(3):195-8.

2. Doyle L: Gabriel Andral (1797-1876) and the first reports of lymphangitis carcinomatosa. J R Soc Med 1989, 82(8):491-3.

3. Bruce DM, Heys SD, Eremin O: Lymphangitis carcinomatosa: a literature review. J $R$ Coll Surg Edinb 1996, 41(1):7-13.

4. Yamagishi $Y$, Akiba $Y$, Izumiya M, Higuchi $H$, lizuka $H$, Takaishi $H$, Nagata $H$, Hibi T: [A case of advanced gastric cancer with lymphangitis carcinomatosa after operation of Krukenberg tumor treated by TS-1 plus CPT-11 as third-line chemotherapy]. Gan To Kagaku Ryoho 2005, 32(8):1167-70.

5. Gupta PR, Joshi N, Meena RC, Ali M: Asymptomatic lymphangitis carcinomatosis due to squamous cell lung carcinoma. Indian J Chest Dis Allied Sci 2005, 47(2):121-3.

6. Thomas A, Lenox R: Pulmonary lymphangitic carcinomatosis as a primary manifestation of colon cancer in a young adult. CMAJ 2008, 179(4):338-40.

7. Kirk JE, Kumaran M: Lymphangitis carcinomatosa as an unusual presentation of renal cell carcinoma: a case report. J Med Case Reports 2008, 2:19.

8. Yang SP, Lin CC: [Pulmonary lymphangitic carcinomatosis]. Taiwan Yi Xue Hui Za Zhi 1968, 67(9):361-74.

9. Zhang $K$, Huang $Y$ : [Clinical features and diagnosis of pulmonary lymphangitic carcinomatosis]. Ai Zheng 2006, 25(9):1127-30.

10. Prakash P, Kalra MK, Sharma A, Shepard JA, Digumarthy SR: FDG PET/CT in Assessment of Pulmonary Lymphangitic Carcinomatosis. AJR Am J Roentgenol 2010, 194(1):231-6.

11. Kikuchi N, Shiozawa T, Ishii $Y$, Satoh H, Noguchi M, Ohtsuka M: A patient with pulmonary lymphangitic carcinomatosis successfully treated with TS-1 and cisplatin. Intern Med 2007, 46(8):491-4.

doi:10.1186/1477-7819-9-77

Cite this article as: Babu et al:: A rare presentation of Pulmonary Lymphangitic Carcinomatosis in Cancer of Lip: Case Report. World Journal of Surgical Oncology 2011 9:77.

\section{Submit your next manuscript to BioMed Central and take full advantage of:}

- Convenient online submission

- Thorough peer review

- No space constraints or color figure charges

- Immediate publication on acceptance

- Inclusion in PubMed, CAS, Scopus and Google Scholar

- Research which is freely available for redistribution

Submit your manuscript at www.biomedcentral.com/submit
C Biomed Central 